\title{
VALORIZATION OF WASTE FROM AGRO-INDUSTRY USING THERMO-CHEMICAL TREATMENTS
}

\author{
ADELITZA STRUBINGER, JOUSSIE OYOQUE, VALERIA GONZÁLEZ \& JULIA GUERRA \\ Universidad Simón Bolívar, Venezuela
}

\begin{abstract}
The increasing generation of solid waste and the interest in renewable and alternative energies has become goals in recent years. The objective of this work was to apply thermochemical conversion processes such as pyrolysis, and hydrothermal conversion (HTC and HTL) into waste from the industry such as the coffee husk $(\mathrm{CH})$, and orange peel $(\mathrm{OP})$ in order to determine their performance towards the production of biocarbon, distribution of organic liquid products, as well as characterization of the bio carbon, obtained. Pyrolysis treatments were carried out with a rapid heating ramp up to $500^{\circ} \mathrm{C}$, HTC at $250^{\circ} \mathrm{C}$, and $\mathrm{HTL}$ at $280^{\circ} \mathrm{C}$ for 4 hours in triplicates for each biomass. The highest bio carbon yield for OP was obtained by HTC with $36 \% \mathrm{w} / \mathrm{w}$ and for $\mathrm{CH}$ the pyrolysis with $40 \% \mathrm{w} / \mathrm{w}$. The biocarbon obtained from the OP by pyrolysis has a high potential as fuel with a higher heating value (HHV) of $26,3 \mathrm{MJ} / \mathrm{kg}$. On the other hand, in the $\mathrm{CH}$ processed by HTC and HTL reported HHV values of 23 $\mathrm{MJ} / \mathrm{kg}$. The processing by HTC and HTL favours the formation of biocarbon with high iodine and methylene blue (MB) indices compared to a commercial carbon, for the OP the values obtained are: 343 and $416 \mathrm{mg} \mathrm{I} / \mathrm{g}$, and 174 and $188 \mathrm{mg} \mathrm{MB} / \mathrm{g}$ whereas for CH 432 and $427 \mathrm{mg} \mathrm{I} / \mathrm{g}$, and 264 and $173 \mathrm{mg} \mathrm{AM} / \mathrm{g}$. In relation to liquid organic products, the processing of OP induces the formation of organic compound fractions in the gasoline and diesel range (GRO+DRO) with values between 75$78 \%$ when the heat treatments are employed. For the $\mathrm{CH}$, the highest fraction of GRO+DRO was obtained from the pyrolysis with $81 \%$. The HTC obtained the lowest sulphur content for both processed biomass, where the values did not exceed $0.066 \% \mathrm{w} / \mathrm{w}$.
\end{abstract}

Keywords: biomass, pyrolysis, hydrothermal conversion, biocarbon.

\section{INTRODUCTION}

Energy policies in developed countries concentrate on reducing the dependence on fossil fuels, have promoted new technologies for the utilization of biomass as renewable raw. This is organic matter originated in a biological process, usable as an energy source [1].

A variety of thermochemical or a biological process, with the absence of oxygen, is being used to convert biomass to products with higher carbon content than the original biomass. Gaseous products or liquids (alcohol, biogas, and biofuels) predominate in the biochemical transformations, while the solid (carbon) is the main commercial products of pyrolysis which occur every year several million tons of carbon [2]. Pyrolysis is a technology that allows it with a low emission of gaseous pollutants, and few liquid effluents, as well as allowing a better energy and material recovery of the used biomass [3].

The advantage of hydrothermal processes is that can convert input material with high moisture content in carbonaceous solids with relatively high yields, without the necessity for intensive drying. These processes are also able to produce high-quality fuels and materials with different characteristics than their dry counterparts [4].

Researchers have focused on efficiently utilize abundant biomass available as residues of the different production processes to benefit humanity. However, millions of tons of biomass every year end up discarded in landfills, and dumps open generating products of decomposition or degraded by microorganisms [5]. 
The conversion of biomass into fuels and chemicals can save foreign currency reserves and boost economic activity in the regions of the world that lack the resources of fossil fuels and have abundant biomass [6].

The objective of this research is to study the effect of variables in thermal processes used in biorefining on the performance and characteristics of the products for the biomass of coffee husk and orange peel using laboratory-scale reactors. Characterize the physicochemical properties of biocarbon's and biofuels generated in the different treatments to interpret, compare and establish the treatment and optimal operating conditions that allow a greater energy evaluation of the biomass studied.

\section{EXPERIMENTAL METHODOLOGY}

\subsection{Thermochemical Processes in reactor by load}

The samples of residues selected in this study are coffee husk and orange peel. A portion of $2-3 \mathrm{~kg}$ of both residues was selected and homogenized. The coffee husk was subjected to a sieving process to obtain a particle size $<2 \mathrm{~mm}$. The selected orange peels were dried at room temperature for about one week. Their particle size was reduced by cutting the material and subsequently dried at $60^{\circ} \mathrm{C}$ for about $12 \mathrm{~h}$. The same was then sieved for a final particle size $<2 \mathrm{~mm}$.

The thermochemical process carried out in a batch reactor laboratory scale stainless steel Parr $500 \mathrm{ml}$ capacity, model 4652. All experiments were performed in duplicate. Table 1 presents the experimental conditions of each process.

Slow pyrolysis was used with a heating rate of $3-5^{\circ} \mathrm{C} / \mathrm{min}$ from room temperature to 500 $\pm 10^{\circ} \mathrm{C}$. After reaching this temperature the condition is maintained for $1 \mathrm{~h}$. The condensable products were collected by a cooling system at the outlet of the reactor.

HTC and HTL were performed in the same reactor but at autogenous system pressure. A heating rate of $3-5^{\circ} \mathrm{C} / \mathrm{min}$ was used up to $250 \pm 5^{\circ} \mathrm{C}$ for $\mathrm{HTC}$, and the same heating ramp up to $280 \pm 5^{\circ} \mathrm{C}$ for HTL. After reaching these temperatures the condition is maintained for $4 \mathrm{~h}$, and the pressure reached by the system is recorded. For each test the non-condensable gas sample was collected for further characterization by gas chromatography.

\subsection{Product separation}

The liquid products of HTC and HTL are treated by liquid-liquid extraction using dichloromethane $\left(\mathrm{CH}_{2} \mathrm{Cl}_{2}\right)$ of analytical quality as a solvent. The solid fraction, characterized by the impregnated biocarbon of condensable products, is washed by a Soxhlet extraction system with $\mathrm{CH}_{2} \mathrm{Cl}_{2}$.

Table 1: Data of the feeds for the processes.

\begin{tabular}{|l|l|c|c|c|}
\hline Process & Description & Mass of Biomass, $\mathrm{g}$ & $\begin{array}{c}\text { Temperature } \\
\left({ }^{\circ} \mathrm{C}\right)\end{array}$ & $\begin{array}{c}\text { Pressure, } \\
(\mathrm{psi})\end{array}$ \\
\hline \multirow{2}{*}{ Pyrolysis } & Coffee husk & $20 \pm 1$ & \multirow{2}{*}{$500 \pm 10$} & Atmospheric \\
\cline { 2 - 3 } & Orange peel & $100 \pm 1$ & \multirow{2}{*}{$250 \pm 5$} & $600 \pm 20$ \\
\hline $\begin{array}{l}\text { Hydrothermal } \\
\text { Carbonization }\end{array}$ & Coffee husk & $25 \pm 1$ & $700 \pm 20$ \\
\hline \multirow{2}{*}{$\begin{array}{l}\text { Hydrothermal } \\
\text { Liquefaction }\end{array}$} & Orange peel & $50 \pm 1$ & $280 \pm 5$ & $900 \pm 20$ \\
\cline { 2 - 3 } \cline { 5 - 5 } & Orange peel & $50 \pm 1$ & $25 \pm 1$ & $1050 \pm 20$ \\
\hline
\end{tabular}


The soluble countable compounds in $\mathrm{CH}_{2} \mathrm{Cl}_{2}$ are brought to constant weight in an oven at 60 $\pm 2^{\circ} \mathrm{C}$ for $48 \mathrm{~h}$.

The fraction of biofuel dissolved in $\mathrm{CH}_{2} \mathrm{Cl}_{2}$ is concentrated by extraction of the solvent by distillation at $45 \pm 1{ }^{\circ} \mathrm{C}$. The resulting fraction is brought to constant weight in an oven at 60 $\pm 2{ }^{\circ} \mathrm{C}$ for $48 \mathrm{~h}$.

\subsection{Characterization of biocarbon and biofuel material}

The moisture content in the biocarbon obtained is determined by weighing $1.5 \pm 0.1 \mathrm{~g}$ of sample and drying at $100{ }^{\circ} \mathrm{C}$ in an oven to obtain constant mass. The determination of the volatile matter contained in the biocarbon is done by the application of COVENIN 1647 (1980). The ash was determined by the name COVENIN 1646 (1980).

The iodine number was performed by placing $0.5 \mathrm{~g}$ of the biocarbon sample in a dark glass bottle and $50 \mathrm{ml}$ of the $0.05 \mathrm{~N}$ iodine concentration solution was added. The solution was then stirred for $24 \mathrm{~h}$. A solution of iodine without biocarbon (blank) and another with reference coal flipped to the same conditions. The iodine number was obtained by the difference between the targets and is expressed as $\mathrm{mg}$ of iodine adsorbed per gram of biocarbon. The methylene blue index was determined in $0.2 \pm 0.1 \mathrm{~g}$ biocarbon in dark glass bottles, $50 \mathrm{ml}$ of methylene blue solution of $350 \mathrm{ppm}$ concentration was added. At the same time, a blank and a reference sample with activated carbon were prepared. The solution was then stirred for $24 \mathrm{~h}$. Subsequently, the concentration of methylene blue in the supernatant was determined with a UV-Visible model Zuzi 4430 spectrophotometer.

For the highest heating value, a PARR calorimeter pump and the measurement protocol described in ASTM D240 (2014) were used.

For the identification of the functional groups of the biocarbon and biofuel samples, the Thermo Fisher Scientific infrared spectrophotometer, model Nicolet iS5, was used in the Fourier transform. Two different methods were used, attenuated total reflectance (ATR), and the total transmission spectrum, for which it prepared $2 \mathrm{mg}$ dry sample pills in $80 \mathrm{mg}$ $\mathrm{KBr}$. Absorbance spectra were averaged, and baseline corrected using the Omnic Spectra software (ThermoScientific).

For the morphological evaluation of the different solid samples an electronic scanning electron microscope model JEOL JSM-6390 was used.

The quantification of the items of interest in the biofuel fraction is done by means of an optical emission spectrometer, the SpectroCiros Vision CCD and the internal normalization technique is applied as a quantification method. The internal standard used was yttrium. Each of the standards and samples was prepared in accordance with the recommendations of ASTM D7691.

The analysis of trace elements in organic matrices was carried out by inductively coupled plasma optical emission spectroscopy, two emission lines were selected per element of interest, more sensitive and less interference, making the background correction on both sides of the signals for each of the lines used.

\section{RESULTS AND DISCUSSION}

\subsection{Study of the performance of products for the different thermochemical processes}

It is observed in Table 2 that for the starting biomass the main non-condensable products and for the gas phase range from $55-66 \% \mathrm{w} / \mathrm{w}$ for the orange peel (OP) and $47-63 \% \mathrm{w} / \mathrm{w}$ for the coffee husk $(\mathrm{CH})$. These results are superior to those reported in the literature [8], [9]. 
Table 2: Products yields of the processes of thermochemical conversion of biomass.

\begin{tabular}{|l|l|l|l|l|}
\hline & \multicolumn{4}{|c|}{ Yields $1,2 \% \mathrm{w} / \mathrm{w}$} \\
\hline \multirow{3}{*}{ Biomass } & Process & Biochar & Biofuel & Biogas \\
\hline \multirow{3}{*}{$\begin{array}{l}\text { Orange } \\
\text { peels }\end{array}$} & Pyrolysis & $39.5 \pm 0.7(1.8)$ & $8.2 \pm 0.6(7.6)$ & $52.3 \pm 0.1(0.1)$ \\
\cline { 2 - 5 } & HTC & $34.9 \pm 0.2(0.5)$ & $17.8 \pm 1.1(6.4)$ & $47.3 \pm 1.3(2.8)$ \\
\cline { 2 - 5 } & HTL & $27.1 \pm 2.4(8.8)$ & $10.8 \pm 0.8(7.4)$ & $63.1 \pm 3.8(4.8)$ \\
\cline { 2 - 5 } & HTC & $36.0 \pm 0.6(1.6)$ & $6.7 \pm 0.5(7.6)$ & $57.3 \pm 1.1(1.9)$ \\
\cline { 2 - 5 } & HTL & $28.5 \pm 1.3(4.6)$ & $17 \pm 0.7(4.0)$ & $54.5 \pm 2.0(3.7)$ \\
\hline
\end{tabular}

${ }^{1}$ The results correspond to the mean value and standard deviation of the replicates.

${ }^{2}$ The values in brackets correspond to the coefficients of variation (\%) for the replicates.

Therefore, it is estimated that the results obtained with high yield in the gas phase can be attributed to the high reaction times in the different treatments (between 1 and $4 \mathrm{~h}$ ), which favours the mechanisms of densification of the biomass and the generation of not condensable fractions with the consequent reduction of the fraction of condensable compounds.

The expected rates of yield for thermal treatments in terms of biocarbon are in intervals between $25-40 \% \mathrm{w} / \mathrm{w}$, which coincides with the results obtained for the two biomasses and is reported in the literature for the equivalent biomass [10]. These results are obtained by the transformation of cellulose and hemicellulose from the biomass into volatile products, while the lignin is converted to carbon because it presents a great stability to the thermal degradation. The observed trend for coffee husk is equivalent to the one that has been most reported in the literature, ie the yield in biofuels decreases between pyrolysis, HTC, and HTL, respectively [10]. The results obtained were higher than those obtained by Li et al. [8] and Tsai et al. [11]. Which reported yields between $27-39 \% \mathrm{w} / \mathrm{w}$. In the orange peel the highest percentage of biochar $(36.0 \pm 0.6 \% \mathrm{w} / \mathrm{w})$ was observed for the HTC. This treatment focuses on the generation of high percentages of biocarbon yield; however, it also favours the decomposition of condensable products more easily than in pyrolytic processes [12]. Although OP yields have not been reported for hydrothermal treatments, Chen and Chen [13], reported a yield of $26.9 \%$ for $500^{\circ} \mathrm{C}$ comparable to the $31.0 \pm 0.1 \% \mathrm{w} / \mathrm{w}$ obtained in the present work at the same temperature.

In relation to the fraction of biofuels, the results obtained were lower than those reported in the literature in equivalent biomasses [3], [10]. This can be attributed to the longer processing time ( 1 to $4 \mathrm{~h}$ ) favoring carbon densification and fractionation of condensed products. In general, the volatile content of the feed marks the yield of the reaction; furthermore, if the ash content is high the yield of the treatment will decrease. For the orange peel, the initial ash percentage reported by Ahmed et al. [14], was 7.34\%; while the initial ash content for the $\mathrm{CH}$ is non-existent according to studies carried out by Bondesson [15].

\subsection{Biocarbon characterization by immediate analysis}

A high volatile content is found for those coming from HTC and HTL compared to pyrolysis, as shown in Table 3. This may be due to incomplete thermal degradation observed in liquefaction as well as in HTC [16]. It also suggests the presence of unstable compounds that can easily be converted into more volatile ones by the various reactions that occur. It is also observed that for the treatments of HTC and HTL the percentage of ashes of the biocarbon was lower in comparison with those obtained by thermal treatment by pyrolysis. 
Table 3: Immediate analysis for the bio carbon product of the thermochemical treatments of the coffee and orange peels.

\begin{tabular}{|l|l|c|c|c|c|}
\hline \multicolumn{2}{|l|}{$\begin{array}{l}\text { Biomass and } \\
\text { Process }{ }^{1,2}\end{array}$} & $\begin{array}{c}\text { Humidity } \\
\%, \mathrm{w} / \mathrm{w}\end{array}$ & $\begin{array}{c}\text { Volatile Matter } \\
\%, \mathrm{w} / \mathrm{w}\end{array}$ & $\begin{array}{c}\text { Ash } \\
\% \mathrm{w} / \mathrm{w}\end{array}$ & $\begin{array}{c}\text { Fixed Carbon, } \\
\% \mathrm{w} / \mathrm{w}\end{array}$ \\
\hline \multirow{3}{*}{$\begin{array}{l}\text { Orange } \\
\text { Peel }\end{array}$} & Pyrolysis & $13.7 \pm 0.6(4.2)$ & $27.1 \pm 0.4(1.5)$ & $8.6 \pm 0.1(1.0)$ & $50.6 \pm 1.0(2.1)$ \\
\cline { 2 - 6 } & HTC & $28.5 \pm 1.4(4.8)$ & $49.7 \pm 0.7(1.3)$ & $2.7 \pm 0.1(2.0)$ & $19.1 \pm 2.1(11)$ \\
\cline { 2 - 6 } & HTL & $21.9 \pm 0.4(1.7)$ & $46.0 \pm 1.1(2.4)$ & $4.2 \pm 0.2(5.6)$ & $28.0 \pm 1.7(6.1)$ \\
\hline \multirow{3}{*}{$\begin{array}{l}\text { Coffee } \\
\text { Husk }\end{array}$} & Pyrolysis & $19.8 \pm 0.3(1.5)$ & $34.3 \pm 0.9(2.5)$ & $13.4 \pm 0.1(0.7)$ & $32.5 \pm 1.2(3.9)$ \\
\cline { 2 - 6 } & HTC & $18.8 \pm 0.9(4.8)$ & $52.3 \pm 2.2(4.2)$ & $6.1 \pm 0.3(5.3)$ & $22.8 \pm 3.4(15)$ \\
\cline { 2 - 6 } & HTL & $20.7 \pm 1.9(9.2)$ & $47.8 \pm 0.4(0.9)$ & $6.3 \pm 0.5(7.8)$ & $25.1 \pm 2.8(11)$ \\
\hline \multicolumn{2}{|l}{ Reference } & $20.5 \pm 1.9(9.1)$ & $46.9 \pm 0.3(0.5)$ & $4.7 \pm 0.1(0.4)$ & $27.9 \pm 2.1(7.7)$ \\
\hline
\end{tabular}

${ }^{1}$ The results correspond to the mean value and standard deviation of the replicates.

${ }^{2}$ The values in brackets correspond to the coefficients of variation (\%) for the replicates.

This result indicates that the hydrothermal treatments in the presence of water at temperatures and subcritical pressures can dissolve part of said matter [17]. When buying the results obtained with a reference carbon, it is observed that after the heat treatment the two evaluated biomasses have better results in terms of the biocarbon yield, being pyrolysis the process that contributes a substantial increase in fixed carbon, which implies the formation of highly condensed and stable compounds [18].

\subsection{Analysis of the higher calorific value of the biocarbon}

The higher heating value (HHV) was determined for the biocarbon obtained from the treatments made to both the orange peel and the coffee husk, in all cases a higher value is obtained with the OP compared to the $\mathrm{CH}$, the results are shown in Table 4. This fact is consistent with what was theoretically expected because the biochar's from the orange peel have a lower ash content, ranging from 1.5 to 2.25 times less ash than in the biochar's obtained from the coffee husk [16].

For HTC and HTL where the conditions of the process, pressure and temperature improves the dehydration, decarboxylation and condensation processes, and lead to the increase of the energy power of the biocarbon because they promote carbon densification, the results alone show an increase in heating value for the coffee husk subjected to HTL [19]. It is therefore considered that the degradation of this biomass leads to the formation of furans and non-cellulose type intermediates, which report a HHV of approximately $22.06 \mathrm{MJ} / \mathrm{kg}$ (5-HMF), while that of the cellulose is $17.58 \mathrm{MJ} / \mathrm{kg}$. Since $5-\mathrm{HMF}$ is produced in hydrothermal processes at the temperatures used, its presence has the capacity to increase the overall heating value of the biocarbon generated.

Table 4: Higher Heating Value for biocarbon produces from biomass.

\begin{tabular}{|l|l|c|c|}
\hline \multicolumn{2}{|l|}{ Biomass and Process } & Higher Heating Value, MJ/kg & Coefficient of Variation, $\%$ \\
\hline \multirow{2}{*}{$\begin{array}{l}\text { Orange } \\
\text { Peels }\end{array}$} & Pyrolysis & $26.3 \pm 0.4$ & 1.6 \\
\cline { 2 - 4 } & HTC & $24.8 \pm 1.2$ & 4.7 \\
\cline { 2 - 4 } & HTL & $24.3 \pm 0.8$ & 3.2 \\
\hline \multirow{2}{*}{$\begin{array}{l}\text { Coffee } \\
\text { Husk }\end{array}$} & Pyrolysis & $21.1 \pm 0.5$ & 2.4 \\
\cline { 2 - 4 } & HTC & $23 \pm 1$ & 4.3 \\
\cline { 2 - 4 } & HTL & $23.5 \pm 0.1$ & 0.4 \\
\hline
\end{tabular}

${ }^{1}$ The results correspond to the mean value and standard deviation of the replicates. 


\subsection{Adsorptive properties}

The results shown in Fig. 1 correspond to the adsorption capacity of iodine per mass of biocarbon obtained. These results indicate that the treatments of orange peel improved the formation of micropores in HTL products. On the contrary, for coals of the coffee husk, no statistically significant differences were observed between the iodine indices of the coals obtained by both HTC and HTL [20].

In general, it is observed that methylene blue index was higher in HTC and HTL than the pyrolysis (Fig. 2), as was also observed for the iodine index. As for the orange peel the results were higher with respect to the reference coal. The HTC for the coffee bean yielded coals with the highest methylene blue index. The adsorption indices that were obtained indicate the presence of macro and mesopores for the biocarbon obtained from the thermal processes applied to the coffee husk, and orange peel, which contribute in the value of the surface area and the adsorptive properties of the material studied.

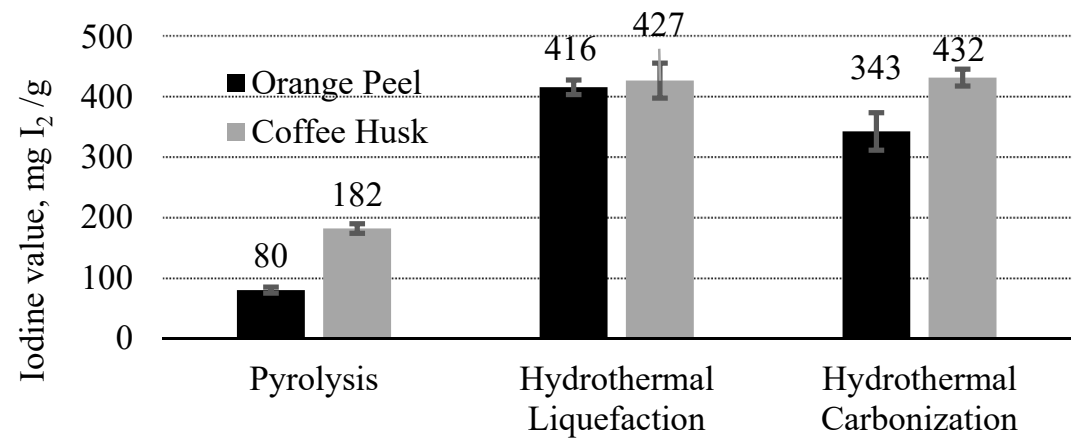

Figure 1: Comparison of the iodine value of the biocarbon for different treatments.

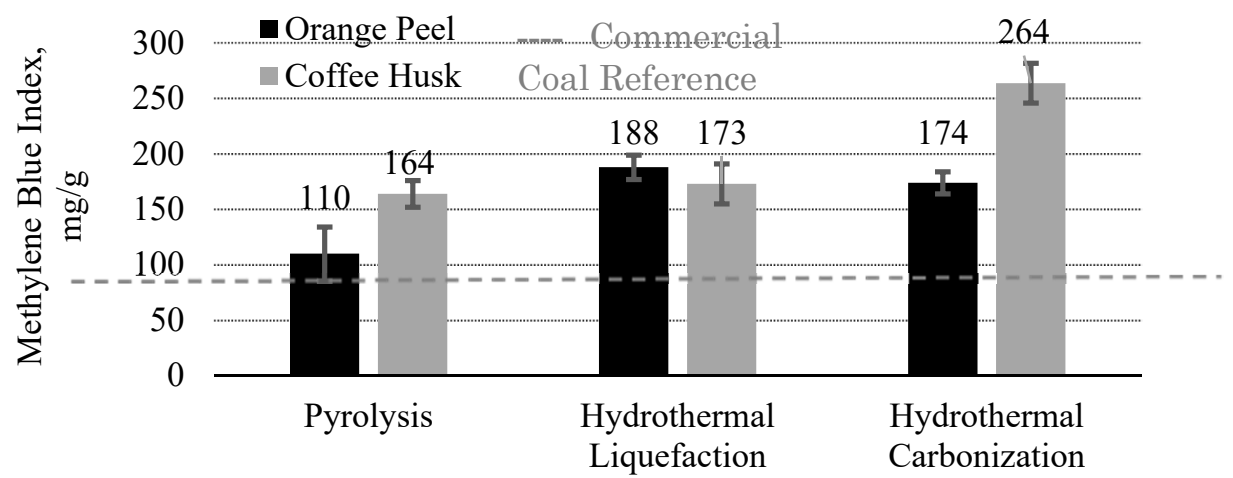

Figure 2: Comparison of the methylene blue index of the biocarbon. 


\subsection{Identification of functional groups by infrared spectrometry Fourier Transform}

In the sample of the biocarbon generated by the biomass of coffee husk, it can be observed (Fig. 3) that in all cases the band from 3600 to $3300 \mathrm{~cm}^{-1}$ is indicative of vibrations corresponding to $\mathrm{OH}$ groups. The frequencies around 3000 and $2850 \mathrm{~cm}^{-1}$ represent the methyl groups terminals; while in 2935 and $2845 \mathrm{~cm}^{-1}$ are the signals of the vibrations of methylene groups. This shows that this process degrades the alkyl chains and that only the functional groups associated with a hard coal or highly densified remain after thermal treatment of anoxic at high temperature $\left(>500^{\circ} \mathrm{C}\right)$.

To minor wave numbers, you can see peaks in the frequency between $1550-1650 \mathrm{~cm}^{-1}$ indicative of aromatic compounds. These may be due to the fact that in these treatments are conditions that give the water properties features that allow you to more easily carry depolymerization, hydrolysis reactions, and decomposition of the biomass [22]. On the band of the $\mathrm{C}=\mathrm{C}$ aromatic notes a small shoulder in the region of $1700 \mathrm{~cm}^{-1}$, which indicates that the biocarbon from hydrothermal reactions with carbonyl groups.
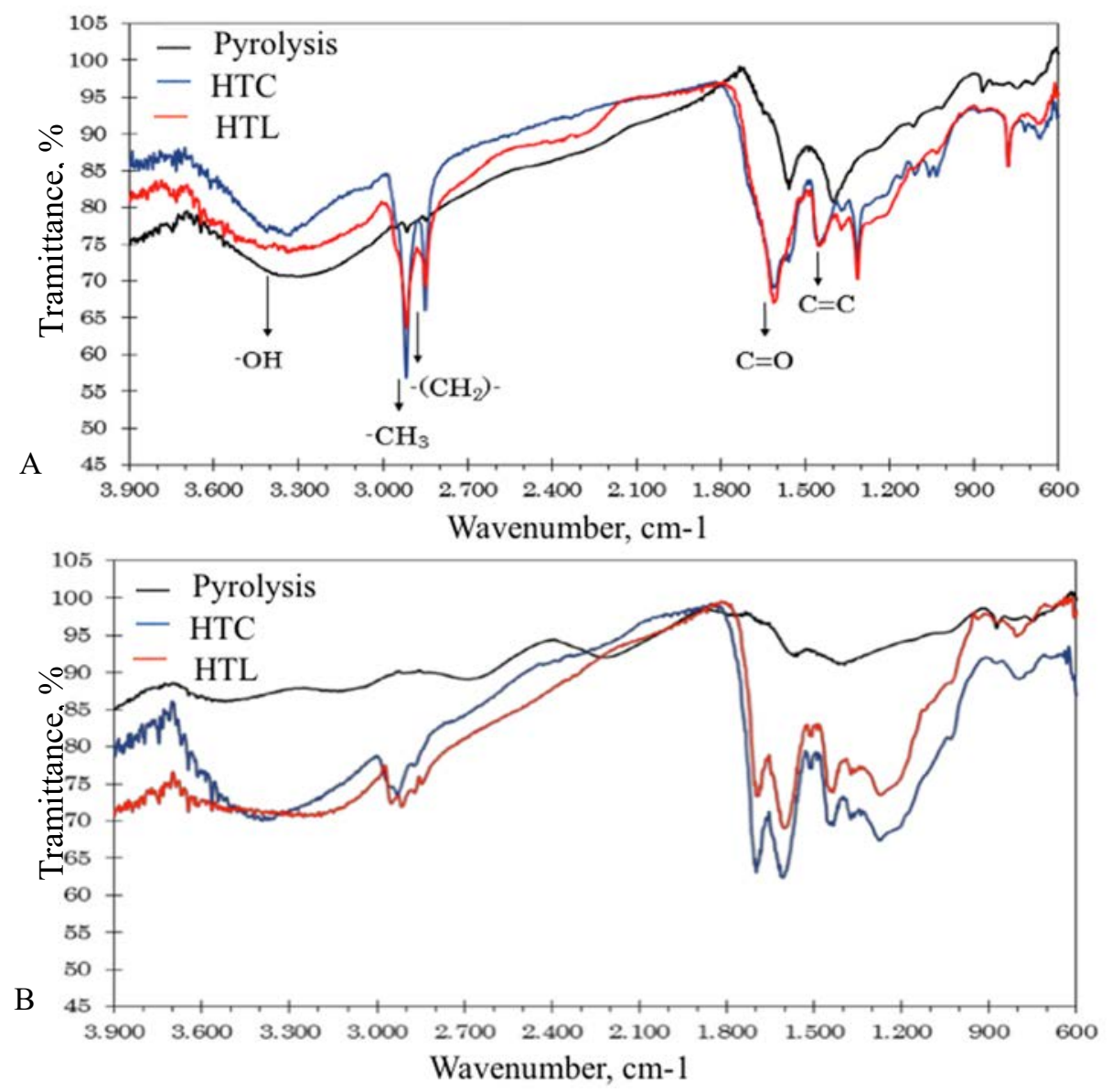

Figure 3: FTIR spectrum of biocarbon obtained. (A) Coffee husk; (B) Orange peel. 

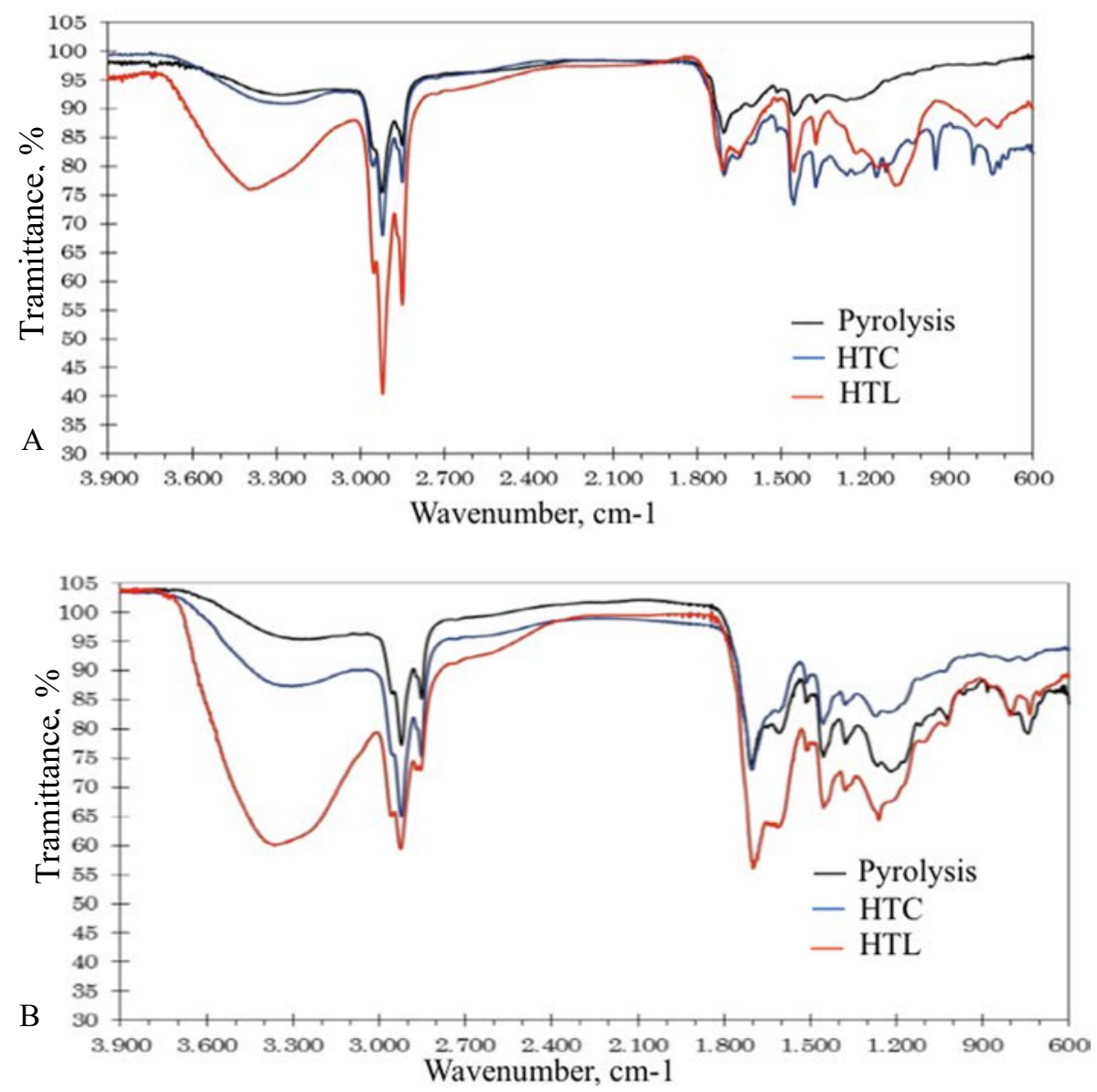

Figure 4: FTIR spectrum of biofuel obtained. (A) Coffee husk; (B) Orange peel.

In the FTIR spectrum obtained for the biocarbon applied to the biomass of orange peel (Fig. 3), is possible to identify the same functional groups reported in the biomass of coffee husk. In this biocarbon is evidence the complete carbonization in the treatment of pyrolysis. The $\mathrm{OH}$ groups present in the orange peel are more susceptible to thermal degradation than those present in the coffee husk. This may be related to the higher proportion of pectin in this raw material since the pectin is a carbohydrate.

In the two-studied biomass it can be observed, in the FTIR spectrum obtained for the biofuels, peaks between 3000 and $2850 \mathrm{~cm}^{-1}$ representative of the vibrations of the methyl groups; while 2935 and $2845 \mathrm{~cm}^{-1}$ are the vibrations of methylene groups (Fig. 4). In addition to them are perceived peaks in the frequency allocations for 1700 and $1730 \mathrm{~cm}^{-1}$ that corroborate the presence of carbonyl groups characteristic of aldehydes, ketones or carboxylic acids. In the different spectrum is displayed that bands corresponding to the formation of carbonyl groups are generally less intense for the treatment of pyrolysis. Typically, the biofuels obtained by high temperatures in the pyrolysis contain more aromatic compounds, less aliphatic compounds [23]. In the spectrum of the fuel obtained from the 
HTL of the coffee husk (Fig. 4) shows a peak in the frequency of $1060 \mathrm{~cm}-1$ corresponding to the elongation and deformation of groups $\mathrm{C}-\mathrm{O}$ [24], which indicates that there are links $\mathrm{CO}$ in the fuel, so the band in the range of 3600 to $3300 \mathrm{~cm}-1$ could also be due to the presence of $\mathrm{OH}$ groups characteristic of alcohols (oligosaccharides product of hydrolysis reactions of cellulose and pectin).

\subsection{Morphology by scanning electron microscopy}

In the original sample of orange peel can be observed an accumulation of dispersed particles of different sizes without defined shapes and agglomerations within the same (Fig. 5). When you submit the biomass pyrolysis heat treatment at high temperatures $\left(500^{\circ} \mathrm{C}\right)$, although there was no significant change in the particle size of the formation of pores, probably a product of the multiform and condensation of particles of different sizes (pores intraparticulares); therefore, it is estimated that increased the surface area of the biocarbon.

The biomass of coffee husk originally consisted of flakes with structured particle size of approximately $500 \mu \mathrm{m}$ (Fig. 5). It can be observed that to be subjected to the treatment of pyrolysis occurred a reduction of particle size, which indicates that at high temperatures and environments without oxygen is generated fractures of these flakes and therefore the particle size decreased to approximately $100 \mu \mathrm{m}$. For the HTC and HTL of the two biomasses analyzed, it was observed that the morphology with respect to the original sample of both change significantly increasing its fragmentation and porosity. This may be due to the release of gases during the devolatilization and the decomposition of chemical bonds of the array of both biomasses [25].
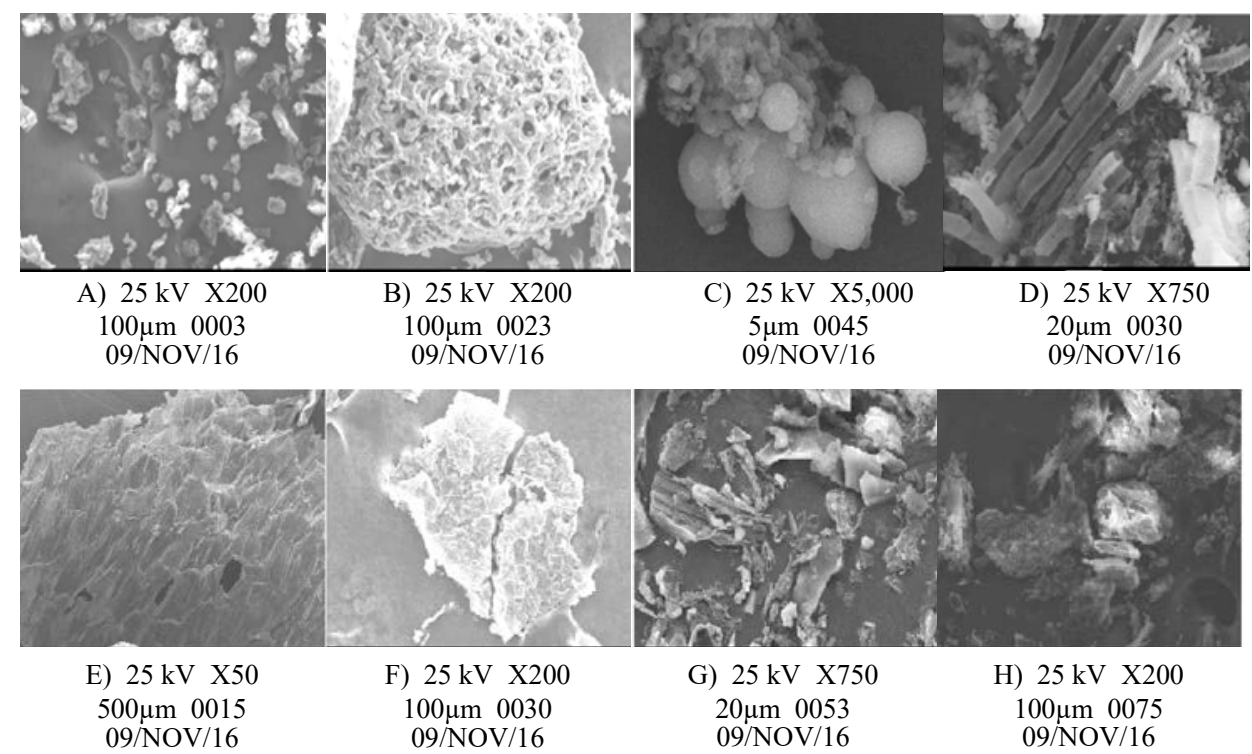

Figure 5: Images of scanning electron microscopy. Orange peel: (A) Original Sample; (B) Pyrolysis; (C) HTL; (D) HTC. Coffee husk: (E) Original Sample; (F) Pyrolysis; (G) HTL; (H) HTC. 


\subsection{Characterization of fractions by gas chromatography}

In general, it was observed (Fig. 6) that the fraction of condensables is mainly constituted by organic compounds in the range of diesel or DRO; which is between $58-73 \%$ for all applied biomass and thermal conversion treatments. The fraction found to a lesser extent corresponds to organic compounds in the boiling range of gasoline (GRO), with values ranging from 5.2 to $16 \%$. In relation to the composition of the condensable fraction, it is expected that the sum of these two fractions will be higher than the heavier fraction or organic compounds in the range of crude (ORO), which effectively is met in all trials.

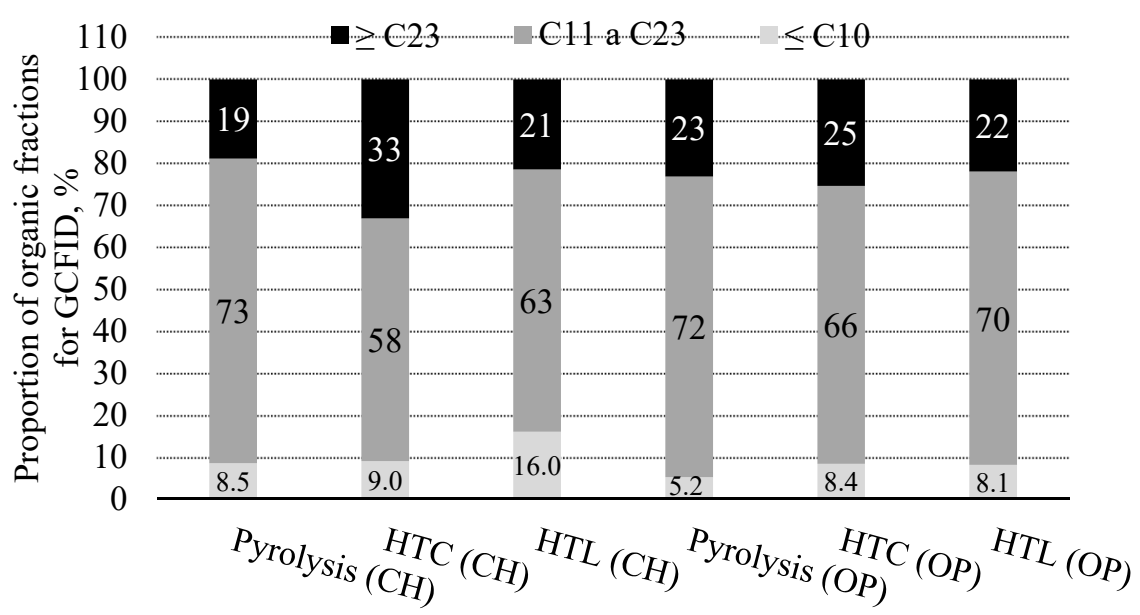

Figure 6: Distribution organic fractions of the condensable.

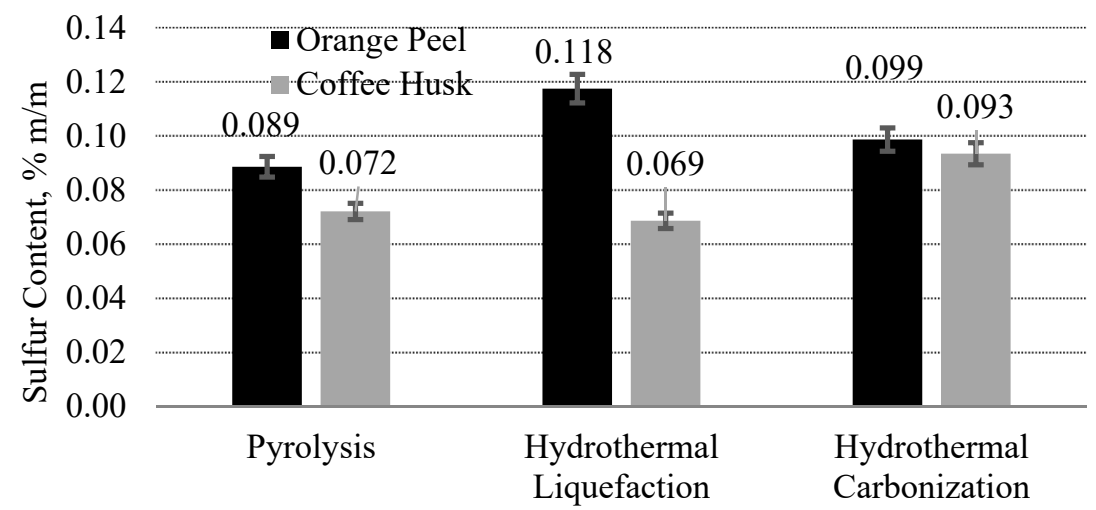

Figure 7: Sulphur content in the condensable. 


\subsection{Content of sulphur and metals}

As for the sulphur content for the orange peel, the treatments used yielded comparable results $(\sim 0.07 \%)$ (Fig. 7). Similarly, for the coffee husk the sulphur content was comparable for all treatments in a $0.1 \%$ approximately. Comparing the two biomasses with the coffee husk would yield a biofuel with the lowest sulphur content of $0.066 \%$. The sulphur content expected for bio-oils is $<0.05 \% \mathrm{~m} / \mathrm{m}$, where both biomass are above this value by which may require a process of desulfurization [22].

The contents of V, Ni, Ag, B, BA, Cd, Cu, Mn, Mg, Sn, Pb, Ti, Cr, Mo, Fe, Zn and P in all cases it was found $<10 \mathrm{mg} / \mathrm{kg}$.

\section{CONCLUSIONS}

Residual times greater than 60 minutes favour the production of biogas and biocarbon, with non-condensable product yields exceeding $52 \% \mathrm{w} / \mathrm{w}$ in both biomasses, while biocarbon yields between $36.0 \pm 0.6 \% \mathrm{w} / \mathrm{w}(\mathrm{HTC})$ and $39.5 \pm 0.7 \% \mathrm{w} / \mathrm{w}$ (pyrolysis), for orange peel and coffee husk, respectively.

The slow pyrolysis in orange peel reports the biocarbon with HHV, being followed by the biocarbon obtained from the coffee husk subjected to HTL. The values obtained are comparable with a conventional fossil fuel.

The properties adsorbed for both the iodine number and the methylene blue index, indicate the formation of mesoporous materials, with values important in adsorption capacity, showing higher biocarbon from the hydrothermal treatments.

The microphotographs indicate the morphological changes undergone by the biomass; in the case of pyrolysis the formation of larger corpuscles is observed indicating the densification of the biomass. While the hydrothermal treatments form fibrous spherical microparticles in the orange peel and for the coffee husk showed the formation of filaments. In the biocarbon obtained by pyrolysis for the coffee husk, it indicates the presence of aromatic groups, whereas hydrothermal treatments identify the presence of $\mathrm{OH}$ groups, and $\mathrm{CO}$ mainly. In the obtained biofuel, the presence of methyl, methylene groups, and carbonyl groups is identified, obtaining a greater proportion when the treatments are hydrothermal in comparison with pyrolysis. In general, it was observed that the fraction of condensable is mainly constituted by organic compounds in the range of diesel or DRO; which is between $58-73 \%$ for all applied biomass and thermal conversion treatments. The two biomasses would yield a biofuel with the lowest sulphur content of $0.066 \%$.

\section{REFERENCES}

[1] Castellanos, P.R., Energías y Medio Ambiente, Ediciones Universidad de Salamanca: 2005.

[2] Antal, M.J. \&Grønli, M., The Art, Science, and Technology of Charcoal Production. Industrial \& Engineering Chemistry Research, 42, pp. 1619-1640, 2003.

[3] Díez, F.Y., Tratamientos Térmicos Asisitidos con Microondas en Procesos de Valorización Energética, 2010.

[4] Libra, J.A., Ro, K.S., Kammann, C., Funke, A., Berge, N.D., Neubauer, Y., Titirici, M.M., Fuhner, C., Bens, O. \& Kern, J., Hydrothermal carbonization of biomass residuals: a comparative review of the chemistry, processes and applications of wet and dry pyrolysis. Biofuels, 2, pp. 71-106, 2011.

[5] Jones, C.W. \& Agrawal, P.K., Hydrogen production from biomass. Google Patents. 2011. 
[6] Akhtar, J. \& Amin, N.A.S., A review on process conditions for optimum bio-oil yield in hydrothermal liquefaction of biomass. Renewable and Sustainable Energy Reviews, 15, pp. 1615-1624, 2011.

[7] García, R., Pizarro, C., Lavín, A.G. \& Bueno, J. L., Biomass proximate analysis using thermogravimetry. Bio-resource technology, 139, pp. 1-4, 2013.

[8] Li, X., Strezov, V. \& Kan, T. Energy recovery potential analysis of spent coffee grounds pyrolysis products. Journal of Analytical and Applied Pyrolysis, 110, pp. 7987, 2014.

[9] Mahinpey, N., Murugan, P., Mani, T. \& Raina, R., Analysis of Bio-Oil, Biogas, and Biochar from Pressurized Pyrolysis of Wheat Straw Using a Tubular Reactor. Energy \& Fuels, 23, pp. 2736-2742, 2009.

[10] Cha, J. S., Park, S. H., Jung, S.-C., Ryu, C., Jeon, J.-K., Shin, M.-C. \& Park, Y.-K., Production and utilization of biochar: A review. Journal of Industrial and Engineering Chemistry, 40, pp. 1-15, 2016.

[11] Tsai, W.T., Liu, S.C. \& Hsieh, C.H., Preparation and fuel properties of biochars from the pyrolysis of exhausted coffee residue. Journal of Analytical and Applied Pyrolysis, 93, 63-67, 2012.

[12] Idris, S.S., Rahman, N.A., Ismail, K., Alias, A.B., Rashid, Z.A. \& Aris, M.J., Investigation on thermochemical behaviour of low rank Malaysian coal, oil palm biomass and their blends during pyrolysis via thermogravimetric analysis (TGA). Bioresource Technology, 101, pp. 4584-4592, 2010.

[13] Chen, B. \& Chen, Z., Sorption of naphthalene and 1-naphthol by biochars of orange peels with different pyrolytic temperatures. Chemosphere, 76, pp. 127-133, 2009.

[14] Aamed, I., Zia, M.A., Hussain, M.A., Akram, Z., Naveed, M.T. \&Nowrouzi, A., Bioprocessing of citrus waste peel for induced pectinase production by Aspergillus niger; its purification and characterization. Journal of Radiation Research and Applied Sciences, 9, pp. 148-154, 2016.

[15] Bondesson, E., A nutritional analysis on the by-product coffee husk and its potential utilization in food production, 2015.

[16] Özçimen, D. \& Ersoy-Meriçboyu, A., Characterization of biochar and bio-oil samples obtained from carbonization of various biomass materials. Renewable Energy, 35, pp. 1319-1324, 2010.

[17] Liu, Z., Quek, A., Hoekman, S.K. \& Balasubramanian, R., Production of solid biochar fuel from waste biomass by hydrothermal carbonization. Fuel, 103, pp. 943-949, 2013.

[18] Brewer, C.E., Biochar characterization and engineering, 2012.

[19] Parshetti, G.K., Hoekman S.K. \& Balasubramaniam, R., Chemical, structural and combustion characteristics of carbonaceous products obtained by hydrothermal carbonization of palm empty fruit bunches. Bio-resource technology, 135, pp. 683689, 2013.

[20] Arbeláez, J.I.M., Janna, F.C., Gutiérrez, C.A.G., Rentería, C.F.V., Velasco, J.O., Blanco, L.A., Marrugo, G., Aguirre, E.Y.O., Monroy, E.F.C. \& Reyes, J.R.A., Biomass Fast Pyrolysis, Universidad Nacional de Colombia: 2013.

[21] Martínez, J.M.R., Lora, E.E.S. \& González, L.N.L., Bioenergía: Fuentes, conversión y sustentabilidad, 2015.

[22] Christensen, P.S., Peng, G.L., Vogel, F. \& Iversen, B.B., Hydrothermal liquefaction of the microalgae Phaeodactylum tricornutum: impact of reaction conditions on product and elemental distribution. Energy \& Fuels, 28, pp. 5792-5803, 2014. 